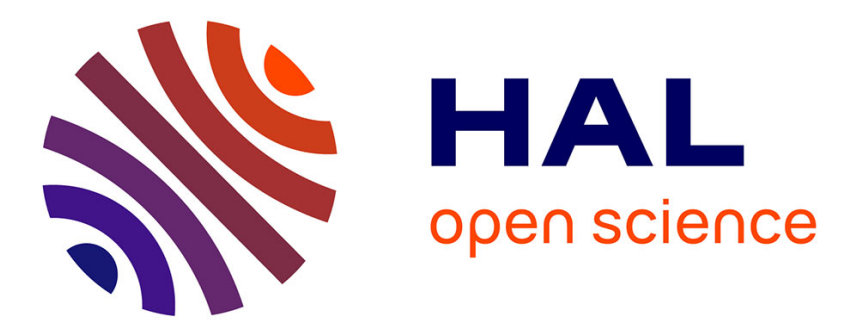

\title{
Variational retrieval of rain profiles from spaceborne passive microwave radiance observations
}

Emmanuel Moreau, Peter Bauer, Frederic Chevallier

\section{To cite this version:}

Emmanuel Moreau, Peter Bauer, Frederic Chevallier. Variational retrieval of rain profiles from spaceborne passive microwave radiance observations. Journal of Geophysical Research, 2003, 108 (D16), 10.1029/2002JD003315 . hal-02950539

\section{HAL Id: hal-02950539 \\ https://hal.science/hal-02950539}

Submitted on 8 Oct 2020

HAL is a multi-disciplinary open access archive for the deposit and dissemination of scientific research documents, whether they are published or not. The documents may come from teaching and research institutions in France or abroad, or from public or private research centers.
L'archive ouverte pluridisciplinaire HAL, est destinée au dépôt et à la diffusion de documents scientifiques de niveau recherche, publiés ou non, émanant des établissements d'enseignement et de recherche français ou étrangers, des laboratoires publics ou privés. 


\title{
Variational retrieval of rain profiles from spaceborne passive microwave radiance observations
}

\author{
Emmanuel Moreau, Peter Bauer, and Frédéric Chevallier \\ European Centre for Medium-Range Weather Forecasts, Reading, UK
}

Received 13 December 2002; revised 24 April 2003; accepted 14 May 2003; published 28 August 2003.

[1] A variational retrieval method has been implemented to evaluate the possibility of assimilating rain-affected microwave radiances in an operational weather forecasting model. The method employs an efficient multiple scattering radiative transfer code and its tangent-linear and adjoint versions to simulate model state equivalent radiances and their sensitivities to changes in hydrometeor contents. Profiles of temperature and humidity together with the ECMWF model convection and cloud schemes are used to produce firstguess hydrometeor profiles. The hydrometeor error covariance matrix is calculated from the operational error covariance matrix of temperature and humidity convolved with both convection and cloud scheme for each profile. A sensitivity study is applied to a tropical cyclone using data from the TRMM Microwave Imager where large differences between the first-guess and observed precipitation fields occurred. The study shows that the approach results in single-column retrievals that compare well with an independent algorithm. A strong dependence of the analysis on the microwave frequencies chosen as observations was noted. This was especially the case in areas where some microwave channels lost their sensitivity to modifications of the profiles due to saturation or where ambiguous contributions from either cloud droplet absorption or raindrop absorption and scattering were present. Including all channels at 10.7, 19.35, 21.3, and $37.0 \mathrm{GHz}$ produced the lowest number of minimization failures. The failures are either due to strongly non-linear sensitivities of radiances to changes in hydrometeor contents for a given profile or due to areas where the channel dependent spatial resolution produces inconsistent observations. INDEX TERMS: 3337 Meteorology and Atmospheric Dynamics: Numerical modeling and data assimilation; 3354 Meteorology and Atmospheric Dynamics: Precipitation (1854); 3360 Meteorology and Atmospheric Dynamics: Remote sensing; KEYWORDS: Variational, retrieval, precipitation, microwave observation

Citation: Moreau, E., P. Bauer, and F. Chevallier, Variational retrieval of rain profiles from spaceborne passive microwave radiance observations, J. Geophys. Res., 108(D16), 4521, doi:10.1029/2002JD003315, 2003.

\section{Introduction}

[2] The assimilation of satellite derived rain rates in numerical weather prediction (NWP) models has made important progress during the last decade due to advances in data assimilation techniques and the availability of improved satellite instruments [Treadon, 1997; Hou et al., 2000; Krishnamurti et al., 2001; Marécal and Mahfouf, 2002]. In particular the variational data assimilation systems [Parrish and Derber, 1992, Courtier et al., 1994] offer a unified framework for the assimilation of any type of observation including spaceborne radiance measurements and retrieved geophysical products. Also, quantitative precipitation retrieval has become much more accurate using new satellite instruments such as the Precipitation Radar (PR) onboard the Tropical Rainfall Measuring Mission (TRMM) and the TRMM Microwave Imager (TMI).

Copyright 2003 by the American Geophysical Union. 0148-0227/03/2002JD003315
[3] Several studies have been carried out at ECMWF to prepare the variational assimilation of rain information. An independent one-dimensional variational retrieval (1D-Var) scheme was implemented using temperature and moisture profiles as control variables. The ECMWF's moist physics package and its Jacobians, i.e., the sensitivity of surface rain rate to changes in moisture and temperature were used in the minimization. As observable, only surface rain rate obtained from TMI data was employed. The analyzed profiles were then transmitted to the four-dimensional framework as pseudo-observations [Marécal and Mahfouf, 2002].

[4] The main results from this exercise can be summarized as follows: (1) A positive impact of rain rates assimilation on both analysis and subsequent forecast [Marécal and Mahfouf, 2002]. (2) When assimilating rain rates mainly moisture was affected while temperature remained almost unchanged [Marécal and Mahfouf, 2002]. (3) Differences between assimilation experiments were caused by both differences in retrieved rain rates and differences in the calculation of the associated errors [Marécal et al., 2002]. (4) Spatial error correlation must be taken into account 
when comparing observed to modelled fields [Bauer et al., 2002a]. (5) The model's moist physics package has to be adapted to reduce non-linearities and to ensure proper minimization [Marécal and Mahfouf, 2003].

[5] As a consequence of these studies, the 1D-Var assimilation of radiances presents an attractive alternative because the system would be more independent of algorithm performance and therefore more flexible with respect to the employed satellite instrument. Additionally, the definition of observation errors is facilitated because these would mainly consist of radiometric noise and radiative transfer modeling errors. Currently, data from the Special Sensor Microwave/Imager (SSM/I) represents the only passive microwave imagery observation that is operationally assimilated at ECMWF in terms of radiances while sounder data from the Advanced Microwave Sounding Unit (AMSU-A) has been assimilated since 1999. In both cases, the assimilation is restricted to clear-sky areas for improving the analysis of atmospheric temperature, moisture, and nearsurface wind speed [Bauer et al., 2002b].

[6] In cloud and rain covered areas, Chevallier and Bauer [2002] have already demonstrated fairly good correspondence of SSM/I radiances from ECMWF model simulations and SSM/I observations. Chevallier et al. [2002] performed first single-column variational retrieval exercises using a limited set of channels from the High-resolution Infrared Radiation Sounder (HIRS) and AMSU-A to demonstrate the positive impact of cloud information on the cloud analysis. This impact was quantified using independent satellite observations.

[7] To introduce the assimilation of rain affected radiances (here in terms of blackbody equivalent brightness temperatures), tb, a sensitivity study is carried out investigating the relative response of microwave frequencies to changes in liquid water and ice concentrations obtained from the ECMWF model's cloud and convection schemes using short-range model forcasted temperature and moisture profiles. An essential step toward the use of there data in rain affected areas is the development of an accurate, fast and linearizable radiative transfer model for the computation of the model-equivalent rain affected radiances that includes the effects of scattering of electromagnetic radiation at hydrometeors. This model and the sensitivities of modelled radiances to changes in hydrometeor contents are introduced in Section 2. A one-dimensional variational retrieval scheme for testing the general performance of a retrieval constrained by the model's first-guess including the available combined cloud-radiative transfer model is presented in Section 3 and tested on a tropical cyclone in Section 4. Section 5 demonstrates the impact of different frequency selections on the analysis and Section 6 summarizes the study and describes the prospects for future assimilation efforts.

\section{Microwave Radiative Transfer}

\subsection{Forward Model}

[8] For simulating the radiative transfer in clouds and precipitation for large data volumes the fast modeling framework RTTOV [Eyre, 1993; Saunders et al., 2001] was chosen because it is also used for all clear-sky simulations at ECMWF. RTTOV employs the fast emissivity model FASTEM-2 [English and Hewison, 1998; Deblonde and English, 2000] for an ocean surface. Multiple scattering contributions are implemented through the Eddington second approximation which has proven to provide sufficient accuracy [Kummerow, 1993]. Comparison to other models of various types have shown small differences of less than $1 \mathrm{~K}$ over ocean for SSMI or TMI sensor configurations [Smith et al., 2002; Moreau et al., 2002].

[9] All hydrometeor types, i.e., rain, snow, cloud liquid water and cloud ice, are modelled as spheres. To increase numerical efficiency, their optical properties are taken from pre-calculated look-up tables. Liquid water permittivity is calculated from the model of Liebe et al. [1989] and ice permittivity from the model of Hufford [1991]. The Rayleigh-approximation is used for the calculation of the optical properties of cloud liquid water and cloud ice assuming monodisperse size distributions. Extinction coefficient, single scattering albedo, and asymmetry parameter of all precipitating particles are calculated from Mie-theory assuming exponential size distributions. More details can be found in Bauer [2001, 2002].

\subsection{Tangent-Linear and Adjoint Models}

[10] For the purpose of variational retrievals, further developments are needed to increase the computational efficiency of the sensitivity calculations. To avoid the explicit calculation of Jacobians from finite differences of tb's between perturbed and reference profiles, the tangentlinear and the adjoint versions of the forward model are required. Let $\mathbf{x}$ represent the model (control) variables and $\mathbf{y}$ represent the computed brightness temperatures, the radiative transfer model $H$ is:

$$
\mathbf{y}=H(\mathbf{x})
$$

The tangent-linear model of $H$, called $\mathbf{H}$, is:

$$
\delta \mathbf{y}=\mathbf{H}(\mathbf{x}) \delta \mathbf{x}=\frac{\partial H(\mathbf{x})}{\partial \mathbf{x}} \delta \mathbf{x}
$$

H computes output perturbations, $\delta \mathbf{y}$, associated to input perturbations, $\delta \mathbf{x}$, assuming a first-order Taylor decomposition of the direct model $H$. The computation time of $\mathbf{H}$ is typically about twice as much as that of $H$. The adjoint model, $\mathbf{H}^{T}$, is then the transpose of the tangent-linear model and computes the sensitivities of $\mathbf{x}$ to perturbations in $\mathbf{y}$. The computation of $\mathbf{H}^{T}$ is only about three to four times slower than the the calculation of $H$. All Jacobians presented here were calculated with the adjoint of the radiative transfer model described above.

\subsection{Jacobians}

[11] A sensitivity study has been carried out to investigate the relative response of microwave tb's to changes in cloud/ rain water and ice concentrations based on ECMWF model data. The model variables are produced from a 3-hour forecast (using cycle 23R4 of the operational ECMWF forecast system) with spectral truncation $T_{L} 511 L 60$ corresponding to $\approx 40 \mathrm{~km}$ grid resolution and 60 vertical levels between surface and top of the atmosphere. Tropical cyclone MITAG located in the Western Pacific on March 5, 2002, was selected. Figure 1 shows the surface rain rates 

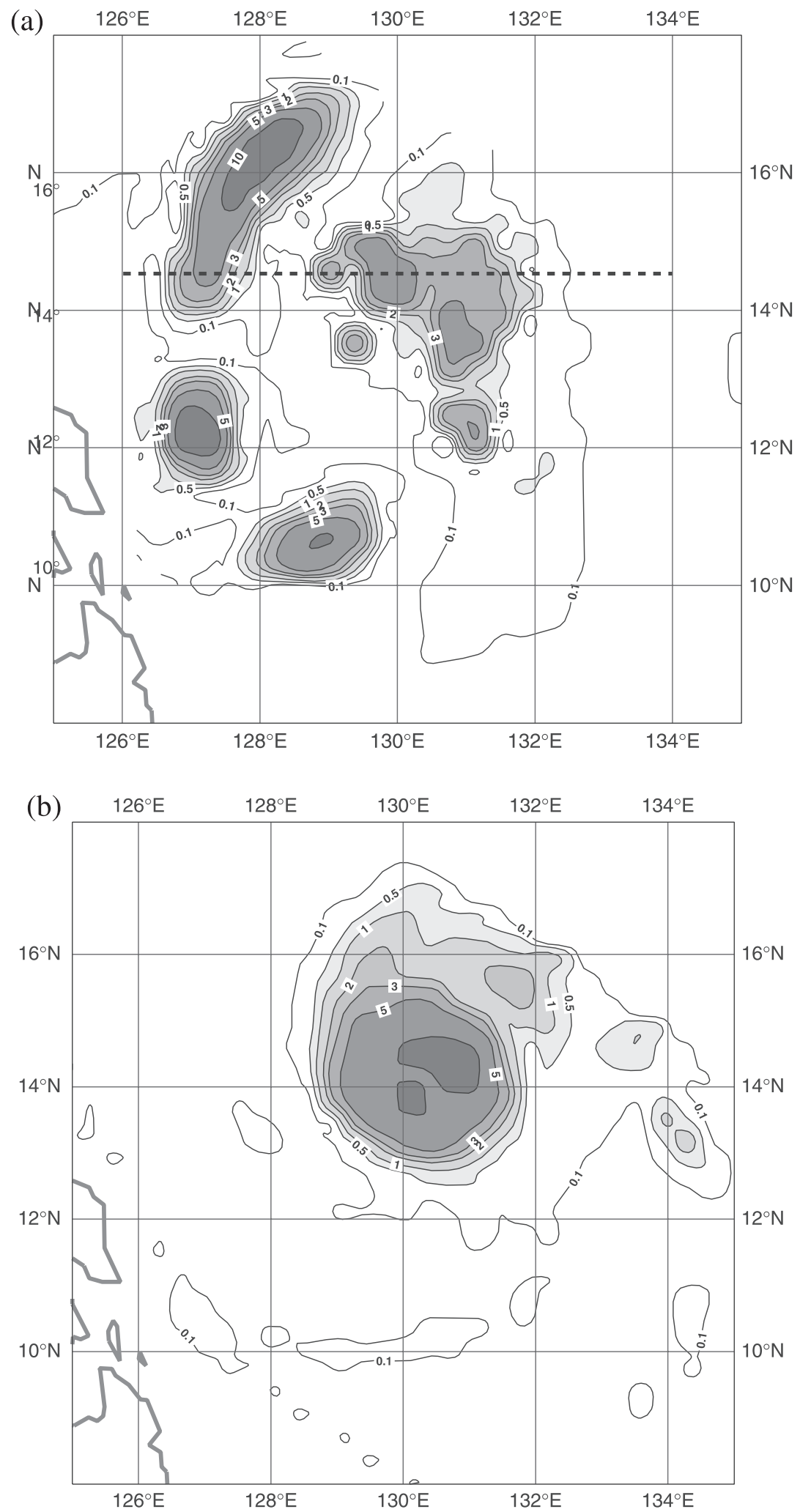

Figure 1. (a) Surface rain rates $\mathrm{mm} / \mathrm{h}$ from the operational $3 \mathrm{~h}$-forecast and (b) 2-km rain rate retrieved with the Bauer et al., [2001] algorithm. The dashed line denotes the cross-section shown in Figures 2-5 and Figure 9.

from the operational 3-hour forecast and near-surface rain rates retrieved from TMI data using the algorithm of Bauer et al. [2001] as well as the position of the cross-section used in the following investigation.
[12] Hydrometeor concentrations of rain $\left(\mathbf{w}_{\mathbf{r}}\right)$ and cloud liquid water $\left(\mathbf{w}_{\mathbf{c}}\right)$ as well as snow and cloud ice are shown Figure 2. Cloud top is located near $16 \mathrm{~km}$ and peak nearsurface rain rates reach $5 \mathrm{~mm} / \mathrm{h}$ (corresponding to about 

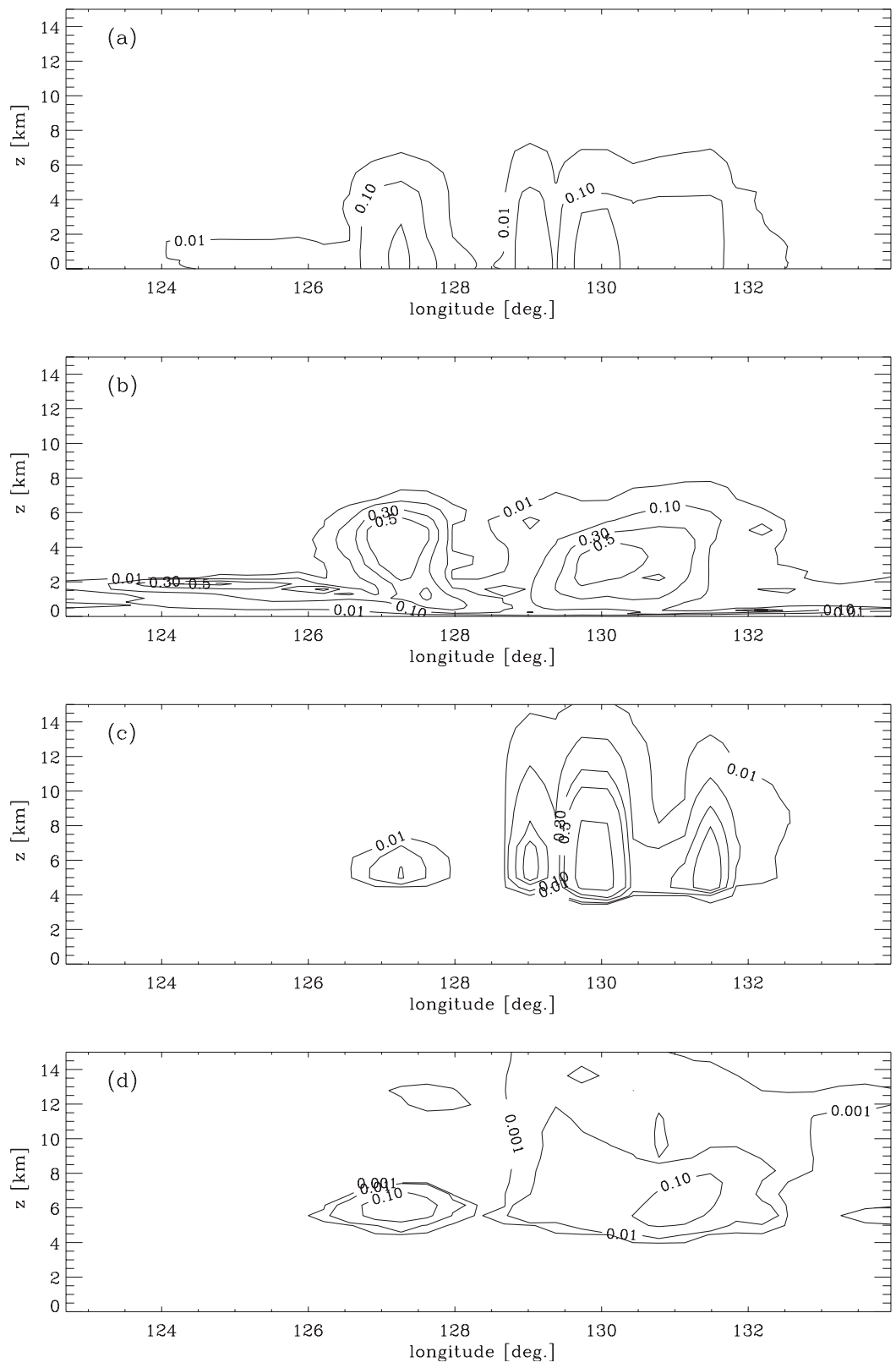

Figure 2. (a) Contents of rain water, (b) cloud liquid water, (c) snow and (d) cloud ice in $g m^{-3}$.

$0.3 \mathrm{gm}^{-3}$ ). Between 4 and $10 \mathrm{~km}$ substantial snow amounts are present. The investigated frequencies are at 10.7, 19.35, $21.3 / 22.235,37.0$ and $85.5 \mathrm{GHz}$ which correspond to those available from SSM/I and TMI radiometers. The Jacobians at the above frequencies with respect to rain liquid water are shown in Figure 3. A variation in rain liquid water content results in a modification of tb's depending on the frequency and on the initial amount of rainwater content. Positive Jacobians may be due to an increasing emission contribution from cloud and raindrops. Negative Jacobians may originate from either an increasing emission above optically thick clouds reducing the effective emission temperature or from scattering at large hydrometeors such as raindrops or frozen precipitation.

[13] In regions of low rainwater content, as for the structure between $124^{\circ}$ and $126^{\circ}$ longitude or near the boundary of the cyclone at $132^{\circ}$ longitude, the Jacobians are positive for frequencies up to $37.0 \mathrm{GHz}$. They are related to areas where particle emission is stronger than scattering. The 37.0 and $19.35 \mathrm{GHz}$ frequencies show the strongest sensitivity to changes in rain water content. In regions of large rainwater content, as in center of the cyclone at longitude $130^{\circ}$ or in the center of the second structure at longitude $127.2^{\circ}$ only the $10.7 \mathrm{GHz}$ channel shows sensitivity to changes in rainwater content, all others channels being saturated. This suggests the usefulness of this channel for retrievals in tropical precipitation regimes.

[14] At 37.0 and $85.5 \mathrm{GHz}$, the Jacobians are negative in the upper part of the rain structure. Below, these channels are not sensitive to any changes in water content. The Jacobians for cloud liquid water are shown in Figure 4. They show a similar behavior with positive values at all frequencies. As for rain, the positive sensitivity is due to the contribution of cloud absorption. Moreover, the Jacobian amplitudes are similar. This highlights the ambiguity of contributions from clouds and rain to the observations. 

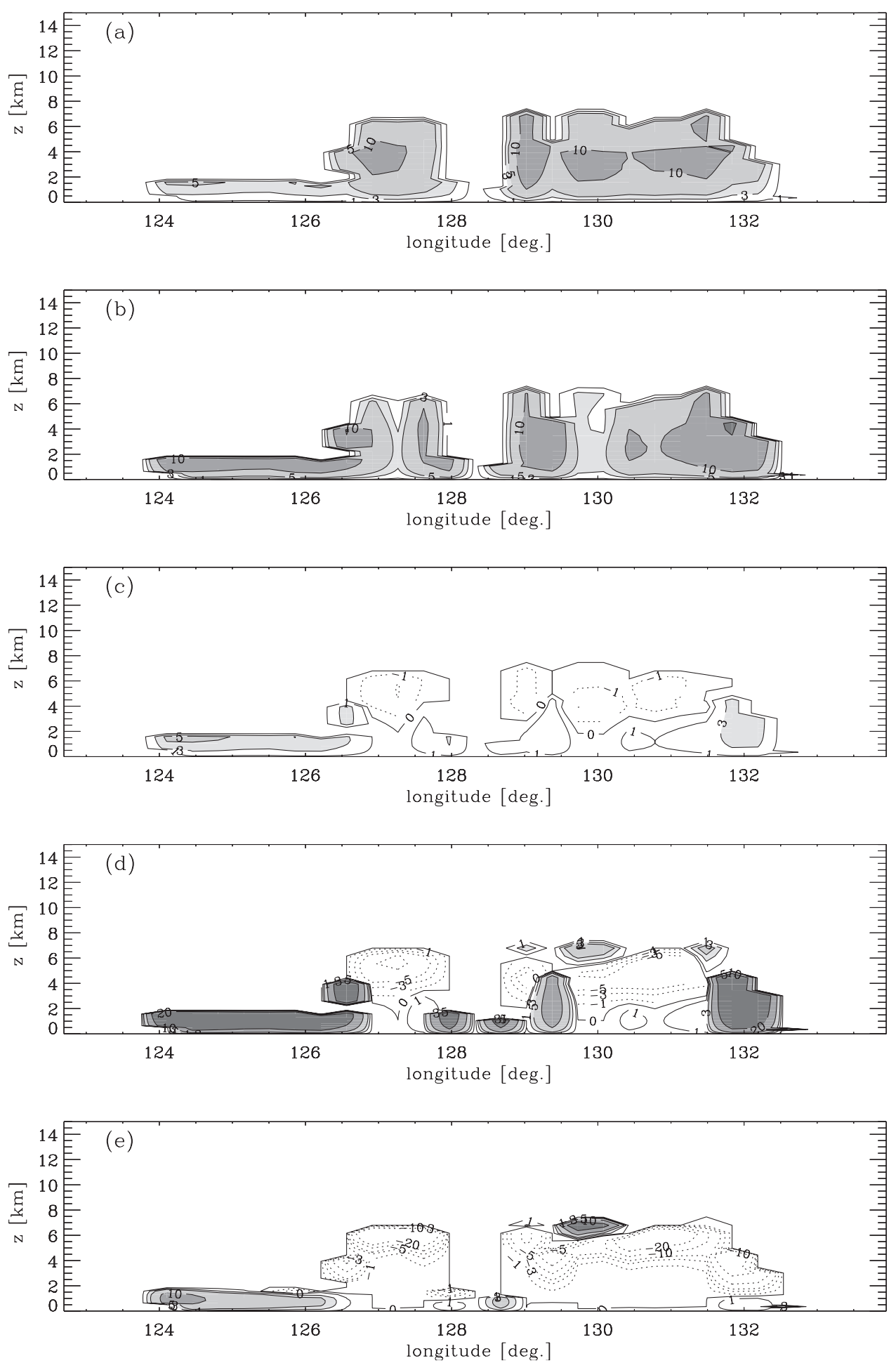

Figure 3. Jacobians for rain water at (a) 10.7, (b) 19.35 , (c) 21.3 , (d) 37.0 and (e) $85.5 \mathrm{GHz}$ in $\mathrm{K} /\left(\mathrm{gm}^{-3}\right.$ ). Shaded areas denote positive Jacobians.

Sensitivities to snow contents are shown in Figure 5. An increase in snow content results in a decrease in tb's at high frequencies where scattering of radiation is very efficient. At lower frequencies, both absorption and scattering by snow are weak resulting in Jacobians near zero.

[15] From these results it is concluded that channels up to $37.0 \mathrm{GHz}$ appear to be the most useful for the variational retrieval of precipitation because: (1) they exhibit a significant sensitivity to rainwater and, (2) they show less sensitivity to snow. The strong sensitivity to cloud absorption, however, suggest that cloud and rain contributions to the total signal are not easily separable. Therefore both must be part of the control vector. The cross-correlation between rain and cloud water has to be considered in the background 

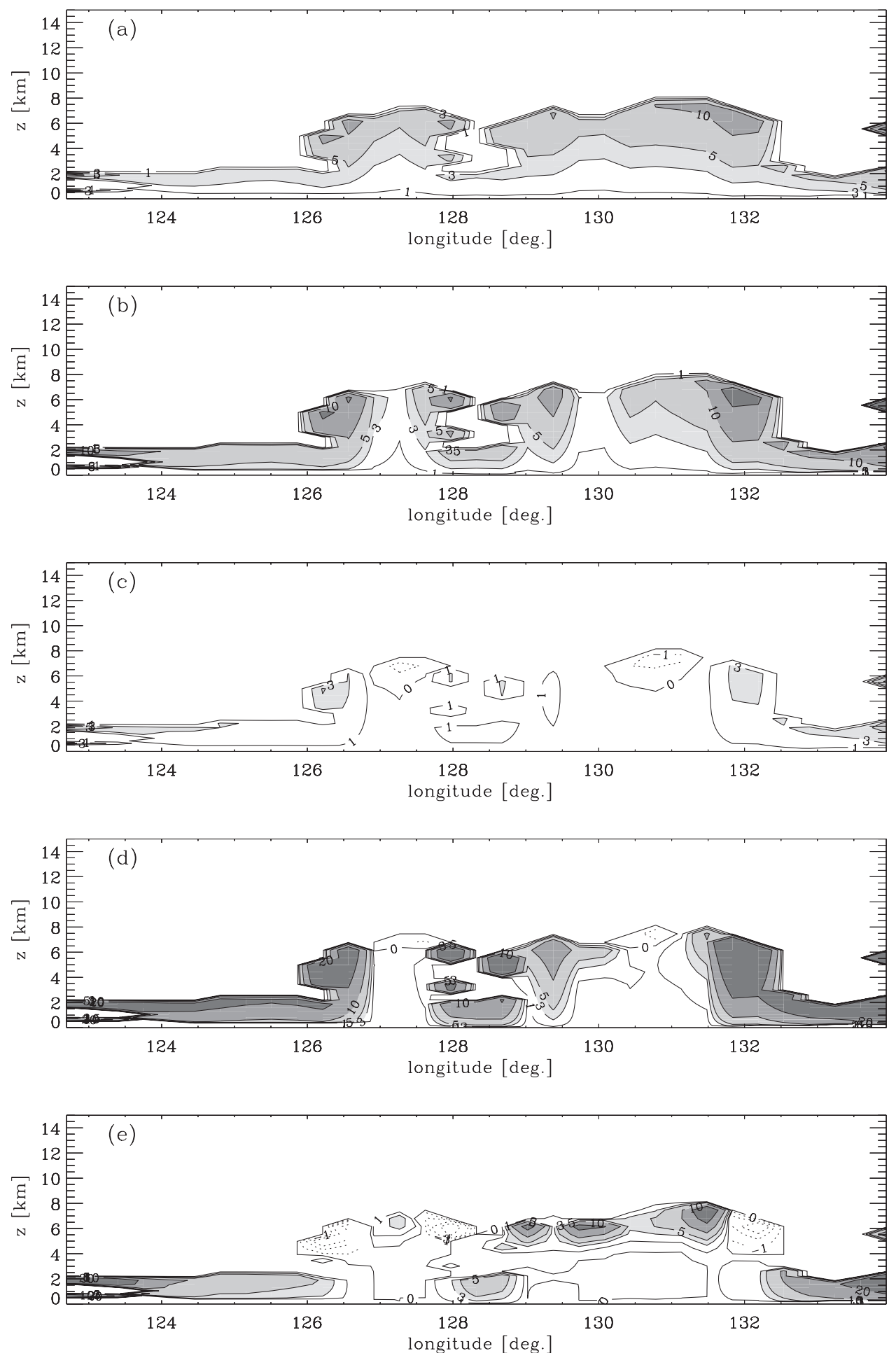

Figure 4. As Figure 3 for cloud liquid water.

error matrix $\mathbf{B}$ to properly relate their relation in the 1D-Var retrieval.

\section{Variational retrieval}

\subsection{D-Var Retrieval}

[16] Let $\mathbf{x}$ be the control vector representing the atmospheric state and $\mathbf{y}$ be the observed brightness temperature vector. The 1D-Var algorithm aims at an optimal balance between $\mathbf{y}$ and $\mathbf{x}$ by finding an optimal state $\mathbf{x}^{a}$ being constrained by the observation, the background state and their errors. Observation and model errors are assumed to be Gaussian, unbiased, and mutually uncorrelated. The departure between an observation $\mathbf{y}^{o}$ and an a priori model state $\mathbf{x}^{b}$ called background (or first-guess) is measured by an objective cost function defined as:

$J(\mathbf{x})=\frac{1}{2}\left(\mathbf{x}-\mathbf{x}^{b}\right)^{T} \mathbf{B}^{-1}\left(\mathbf{x}-\mathbf{x}^{b}\right)+\frac{1}{2}\left(H(\mathbf{x})-\mathbf{y}^{o}\right)^{T} \mathbf{R}^{-1}\left(H(\mathbf{x})-\mathbf{y}^{o}\right)$ 

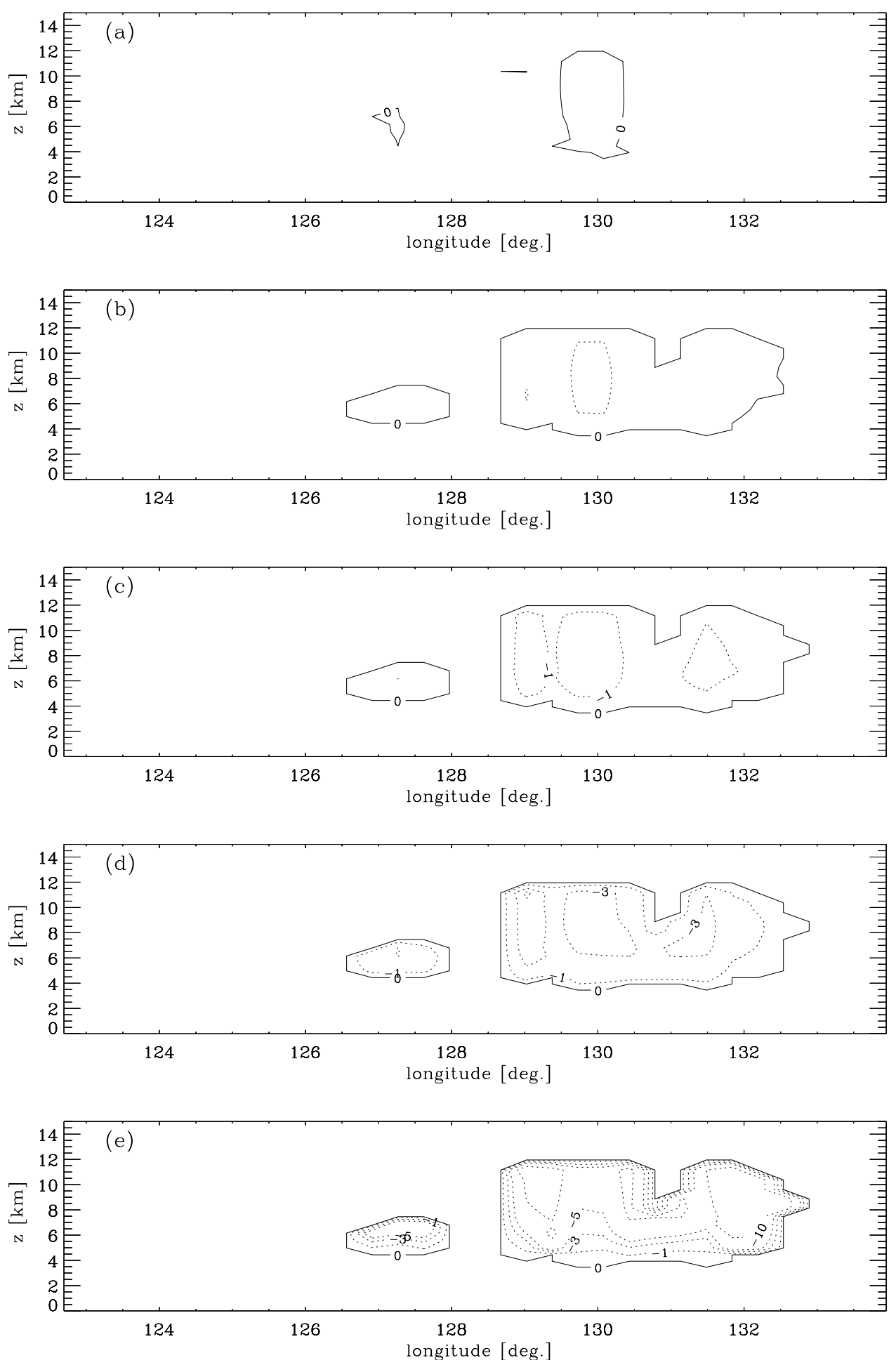

Figure 5. As Figure 3 for snow.

where $H$ is the obervation operator providing the equivalent of the observation to the model state $\mathbf{x}$. B is the background error covariance matrix of state $\mathbf{x}^{b}$, and $\mathbf{R}$ is the observation error covariance matrix (including measurement, representativeness and $H$ errors). Superscripts ' -1 ' and ' $T$ ' denote inverses and transposes, repectively. $H$ is the radiative transfer model described in Section 2. The control vector $\mathbf{x}$ contains vertical profiles of rain and cloud liquid water.
While the relative contribution of temperature and water vapor profiles as well as surface characteristics contribute little to the total signal in clouds and precipitation, frozen hydrometeors should also be part of the control vector. This, however, was not considered because only frequencies with little sensitivity to snow were chosen. It was assumed that this simplification does not cause serious problems unless higher frequencies ( $85 \mathrm{GHz}$ and above) are included. 
[17] The minimization of (3) requires the gradient of $J(\mathbf{x})$ :

$$
\Delta J(\mathbf{x})=\mathbf{B}^{-1}\left(\mathbf{x}-\mathbf{x}^{b}\right)+\mathbf{H}^{T} \mathbf{R}^{-1}\left(H(\mathbf{x})-\mathbf{y}^{o}\right)
$$

where $\mathbf{H}^{T}$ is the adjoint operator of the radiative transfer model. A particular case occurs if there is no rain or cloud liquid water in an atmospheric layer of the background $\mathbf{x}^{b}$. In these cases, the derivatives of the radiances with respect to the control variables are equal to zero and the 1D-Var algorithm would not be able to create rain or cloud water. To avoid this limitation, these values in $\mathbf{x}^{b}$ are replaced by an epsilon value that is $10^{-4} \mathrm{gm}^{-3}$ as in Chevallier et al. [2002]. The minimization module is a limited memory quasi-Newton (M1QN3) software developed by Gilbert and Lemarechal [1989].

\subsection{Error Covariance Matrices}

[18] The background error covariance matrix, B, defines error variances and error correlations of the control variables. Only a few studies have been carried out on the definition of the error covariances of rain and clouds, i.e., $\mathbf{B}\left(\mathbf{w}_{\mathbf{r}}, \mathbf{w}_{\mathbf{c}}\right)$. Lopez [2001] estimated the error covariance matrix of rain and cloud water from the French global model (ARPEGE) based on the National Meteorological Center (NMC) technique [Parrish and Derber, 1992]. This is based on a statistical comparison of forecasts over different time periods assuming that these differences are representative for the error covariances. Chevallier et al., [2002] empirically defined a simple covariance matrix of clouds with rather large errors and Gaussian correlation patterns.

[19] In this study, an alternative approach has been used to compute $\mathbf{B}\left(\mathbf{w}_{\mathbf{r}}, \mathbf{w}_{\mathbf{c}}\right)$ that is based on the error covariance matrix of temperature, $\mathbf{t}$, and humidity, $\mathbf{q} . \mathbf{B}(\mathbf{t}, \mathbf{q})$ is currently used in the operational assimilation procedure of the ECMWF model [Rabier et al., 1997]. First, one hundred perturbed temperature and humidity profiles are generated with magnitudes corresponding to those of the background errors contained in $\mathbf{B}(\mathbf{t}, \mathbf{q})$. The ensemble of perturbed profiles are then used as input to the moist convective and large-scale condensation schemes [Tiedtke, 1989; Tiedtke, 1993, Lopez, Tompkins, Janiskova, pers. communication] for producing an ensemble of perturbed rainwater and cloud liquid water profiles. From these, $\mathbf{B}\left(\mathbf{w}_{\mathbf{r}}, \mathbf{w}_{\mathbf{c}}\right)$ is calculated at each grid point.

[20] An example of $\mathbf{B}\left(\mathbf{w}_{\mathbf{r}}, \mathbf{w}_{\mathbf{c}}\right)$ is presented in Figure 6 where it is decomposed into the error correlation matrix and the standard deviation of rain and cloud water contents. Rainfall rates below cloud base are rather constant and rain production is simulated by a diagnostic approach. Therefore high error correlations occur among rain layers throughout the rain column which increase with increasing distance to cloud top (Figure 6a). A more complex structure of cloud liquid water produces correlations that decrease strongly with distance to the reference level (Figure 6b). The cloud layers are strongly correlated with the rain layers below because of the diagnostic rain generation approach. Close to cloud base, rain production is reduced and cross-correlation decreases (Figure 6c). It has to be noted that the crosscorrelation matrices are non-symmetric. Figure $6 \mathrm{~d}$ shows that the error standard deviations of both rain water, $\sigma_{w}$, and cloud water, $\sigma_{w_{c}}$, are proportional to the rain/cloud water profiles themselves.
[21] A constant observation error covariance matrix $\mathbf{R}$ was defined. It is assumed that there is no correlation between the channels. The observation error, $\mathbf{R}$, takes into account errors from different source, i.e., instrumental noise as well as radiative transfer modeling errors. The accuracy of the TMI measurements is set to $1 \mathrm{~K}$ [Hollinger et al., 1990; Kummerow et al., 1998]. The description of the modeling errors is more complex. The error component associated with the inaccurracy of the Eddington second approximation was quantified from an extensive comparison with a multiple-stream model [Moreau et al., 2002]. Those elements originating from uncertainties of the microphysical parameterizations and the modeling of cloudinhomogeneity can only be roughly estimated [Tassa et al., 2003]. Therefore rather large errors were assumed, that is $3 \mathrm{~K}$ for all frequencies in vertical polarization and $6 \mathrm{~K}$ in horizontal polarization due to the difference in dynamic range between the polarizations (see Table 1). In the future, a more complex approach for a better estimation of observation errors will be required, in particular for the inclusion of error correlations. This, however, will require the employment of three-dimensional Monte Carlo radiative transfer simulations to estimate the errors due to the approximations on sub-grid scale variability. The estimation of errors originating from the assumptions on cloud microphysics may also use ensembles of perturbed profiles to calculate the variance in observation space.

\section{Results}

[22] For tropical cyclone MITAG, TMI-observations were co-located with the model grid by choosing the observation closest to the center of the corresponding model grid box, respectively. The average temporal difference between observation and model output was limited to less than one hour. Only situations where background and/or observation contained rain were chosen. To classify a situation as rainy from the observation, a simple test based on the difference of the observed brightness temperature at $37 \mathrm{GHz}$ at vertical and horizontal polarization, i.e., $t b_{37 v}-t b_{37 h}<40 \mathrm{~K}$, was used. Since the observation operator is non-linear, the minimization procedure cannot always converge to a unique solution. For this purpose, another criterion was defined to accept only those retrievals for which:

$$
\sum_{k=1}^{n} \frac{\left[t b^{a}(k)-t b^{o}(k)\right]^{2}}{[3 * \sigma(k)]^{2}} \leq 1
$$

where $n$ is the number of observation and $\sigma$ the standard deviation of the observation error according to $\mathbf{R}$. In case of rejection, the analyzed profile is replaced by the background. These infrequent cases correspond to situations with very high rain rates in the background where most of the channels are saturated. These are marked by white crosses in Figures 7 and 8. The 1D-Var retrievals presented in this section use TMI tb's at $19.35 \mathrm{GHz}$ (vertically and horizontally polarized) and at $21.3 \mathrm{GHz}$ (vertically polarized) as observations. These channels are denoted $19 \mathrm{v}, 19 \mathrm{~h}, 21 \mathrm{v}$ for the remainder of the paper. This experiment will be used as the control experiment.

[23] Once the 1D-Var method has been applied to the background state, that is after the minimization, analyzed 

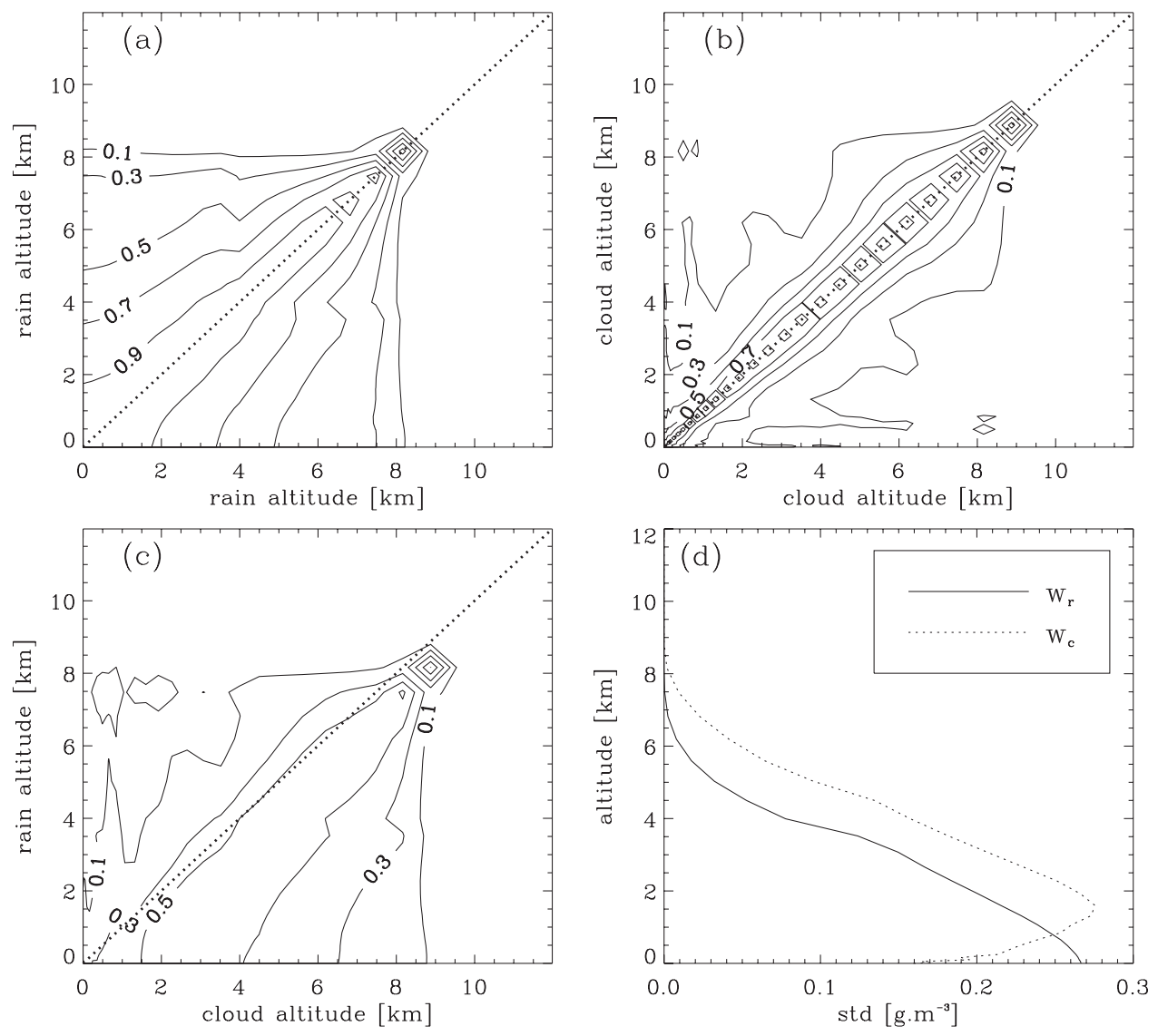

Figure 6. (a) Vertical correlation of rain water profile, (b) cloud liquid water profile. (c) Vertical crosscorrelation between cloud liquid and rain water. (d) Profile of errors of rain and cloud liquid water.

radiances $\left(\mathbf{t b}^{a}\right)$ are available. The $\mathbf{t b}^{a}$ are first compared to the observations $\left(\mathbf{t b}^{o}\right)$ to verify the good convergence of the minimization. Table 1 presents both background $\left(\mathbf{t b}^{b}-\mathbf{t b}^{b}\right)$ and analysis departures $\left(\mathbf{t b}^{o}-\mathbf{t b}^{a}\right)$ for the three considered channels. The background radiances $\left(\mathbf{t b}^{b}\right)$ are computed from the background state. For all channels the background departures are quite large with root-mean-square differences (errors), rmse s, of $17.2,33.6$ and $9.2 \mathrm{~K}$ at $19 \mathrm{v}, 19 \mathrm{~h}$ and $21 \mathrm{v}$, respectively. An efficient 1D-Var retrieval should produce analyzed radiances close to the TMI observation to the level of the accuracy of the observations as defined in the $\mathbf{R}$ matrix. The analysis departures are reduced by $\approx 80 \%$ of the background departures, with rmse s of $1.8,6.3$ and $2.5 \mathrm{~K}$ at $19 \mathrm{v}, 19 \mathrm{~h}$ and $21 \mathrm{v}$, respectively. This means that the minimization worked successfully.

[24] Special attention has to be given to the biases because they are an undesired feature in variational assim- ilation. Observational biases can be attributed to imperfect sensor calibration and drift while model biases may originate from an inadequate physical description of the surfaceatmosphere system as well as biased radiative transfer modeling. Therefore bias-correction schemes may be applied to remove the systematic differences between model generated radiances and observations partly or completely [e.g., Harris and Kelly, 2001]. In case of cloud and rain affected radiances, model biases can be expected which are supposed to be removed by the analysis rather than a biascorrection. From Table 1 it is evident that the biases are significant and that after the 1D-Var retrieval thay are reduced to a third of their first-guess values. The overestimation of rainfall [Chevalier and Bauer, 2003] explains the negative biases. How the four-dimensional assimilation would react to a globally systematic reduction of rainfall and therefore moisture will be the subject of future studies.

Table 1. Control Experiment Statistics ${ }^{\mathrm{a}}$

\begin{tabular}{llrrrrrrrrr}
\hline & & \multicolumn{3}{c}{$19.35 \mathrm{GHz}(\mathrm{v})$} & \multicolumn{3}{c}{$21.3 \mathrm{GHz}(\mathrm{v})$} & \multicolumn{3}{c}{$19.35 \mathrm{GHz}(\mathrm{h})$} \\
\cline { 3 - 12 } & & \multicolumn{1}{c}{ bias } & \multicolumn{1}{c}{ std } & rmse & \multicolumn{1}{c}{ bias } & std & rmse & bias & std & rmse \\
\hline OBS-FG & All pts. & -5.3 & 16.4 & 17.2 & -3.3 & 8.6 & 9.2 & -12.9 & 31.0 & 33.6 \\
OBS-AN & All pts. & -0.3 & 1.8 & 1.8 & -0.5 & 2.4 & 2.5 & -4.4 & 4.5 & 6.3 \\
OBS-AN & $w_{r}^{a}>w_{r}^{b}$ & 0.8 & 1.0 & 1.4 & 0.6 & 1.9 & 2.0 & -1.2 & 2.2 & 2.5 \\
OBS-AN & $w_{r}^{a}<w_{r}^{b}$ & -0.9 & 1.7 & 2.0 & -1.2 & 2.4 & 2.7 & -6.3 & 4.4 & 7.7 \\
\hline
\end{tabular}

${ }^{\mathrm{a}} \mathrm{OBS}$, observation; FG, first-guess; $\mathrm{AN}$, analysis; std, standard deviation; rmse, root mean square error; $w_{r}^{b}$, background rain water content; $w_{r}^{a}$, analysis rain water content; $\mathrm{v} / \mathrm{h}$, vertical/horizontal polarization. All units are in Kelvin. 
ACL $\quad 11-10$
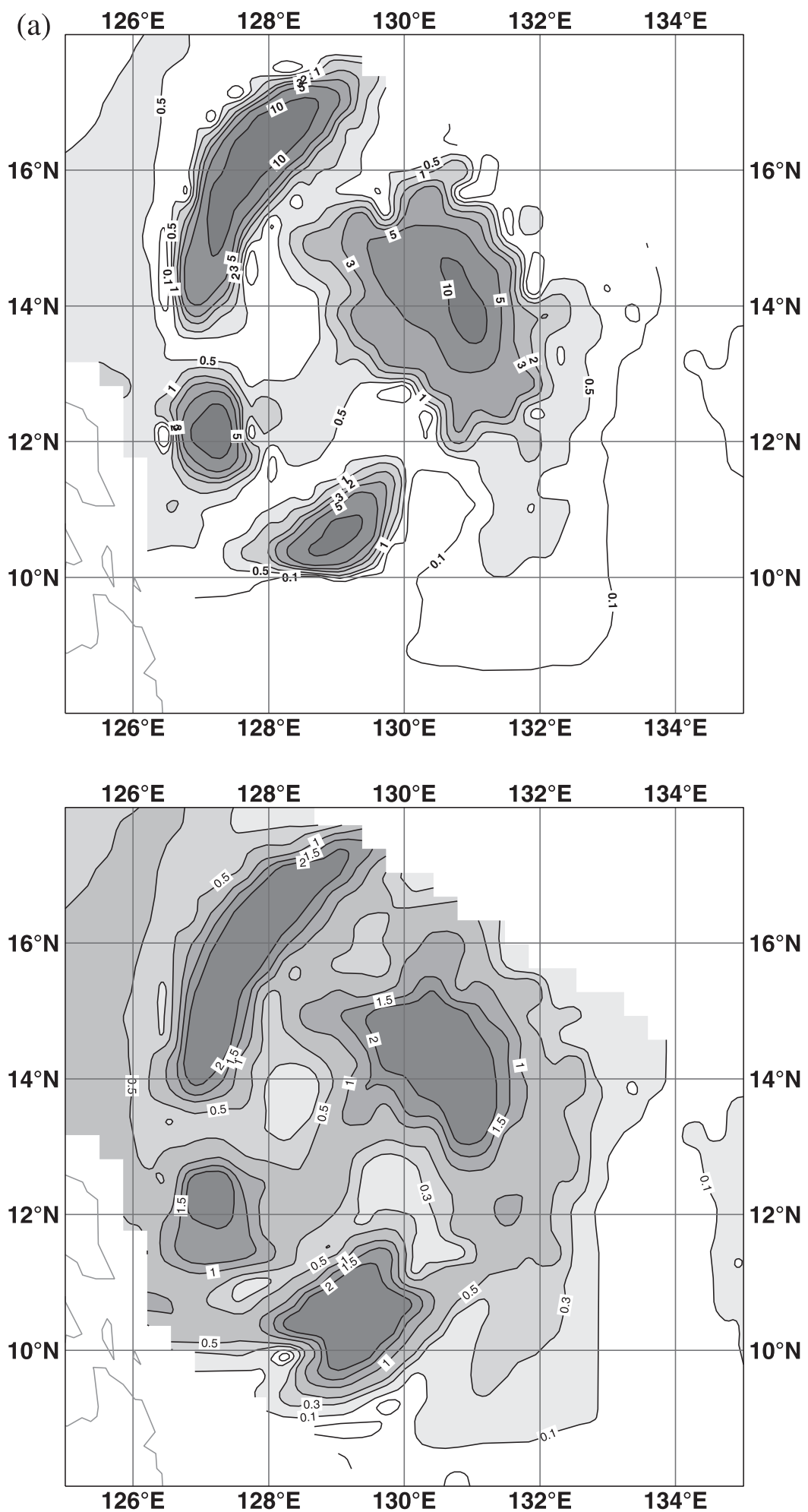

Figure 7. Surface rain rates in $\mathrm{mm} / \mathrm{h}$ (left) and cloud liquid water paths (right) in $\mathrm{kg} \mathrm{m}^{-2}$ from (a) the first-guess and (b) the analysis of the control experiment.

[25] The difference in rmse $\mathrm{s}$ between $19 \mathrm{v}$ and $19 \mathrm{~h}$ can be attributed to the greater sensitivity of the horizontally polarized channel to changes in optical depth due to its larger dynamic range which has been taken into account in the definition of the observation errors. It has to be noted that the minimization is successful in cases where: (1) Analyzed rainwater contents $\left(w_{r}^{a}\right)$ are greater than background rain- water $\left(w_{r}^{a}\right)$ which means that the algorithm has been able to increase rain and cloud water contents. In this cases, the analysis departures are reduced to 1.4 and $2.5 \mathrm{~K}$ at $19 \mathrm{v}$ and 19h (Table 1). (2) $w_{r}^{a}$ is lower than $w_{r}^{b}$. In this cases, the 1DVar retrieval has been able to reduce and possibly switch off the precipitation. The analysis departures increase but still remain close to the values specified in $\mathbf{R}$. 

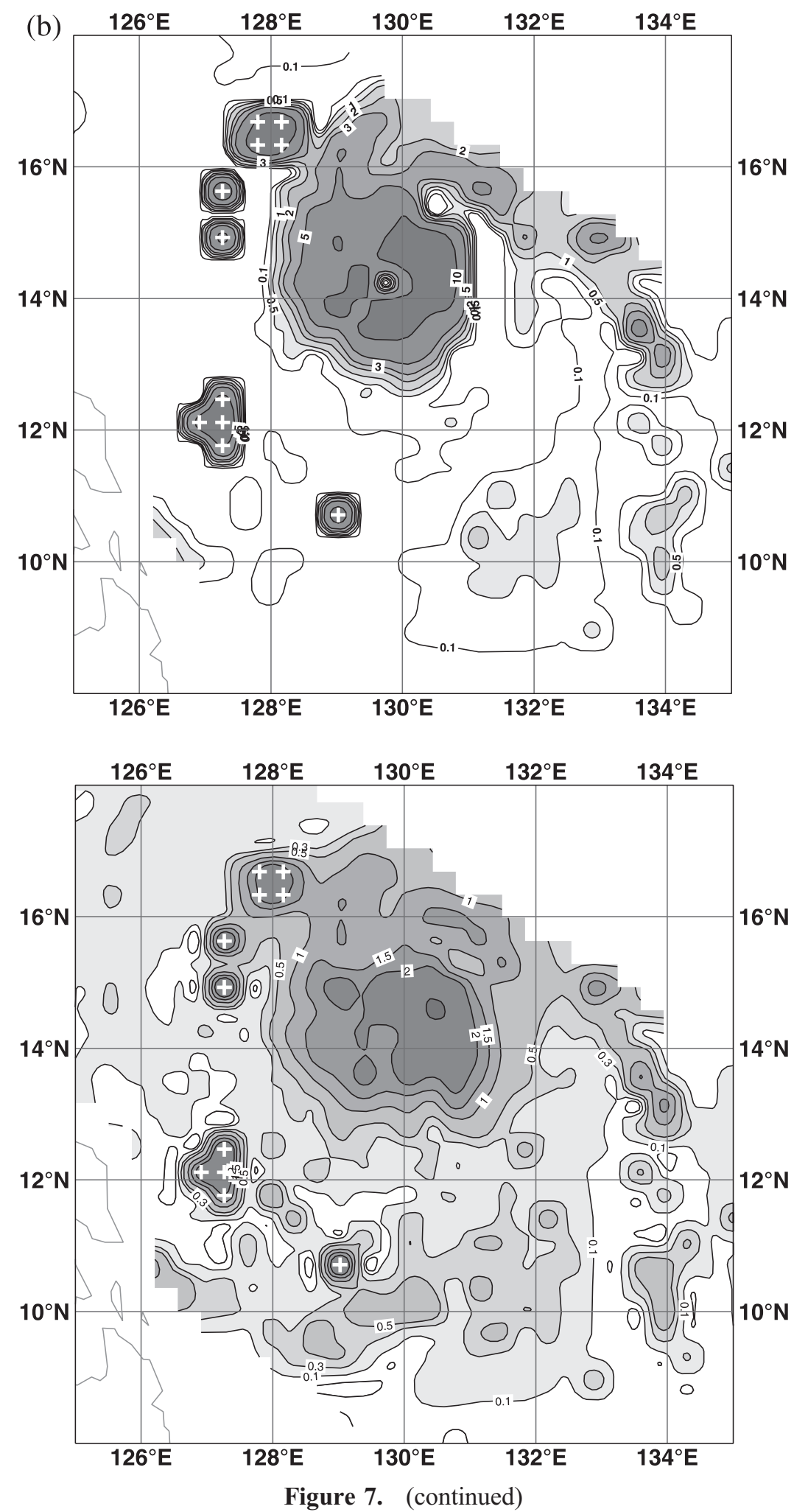

[26] Background and analyzed integrated rain and cloud liquid water paths of MITAG are shown in Figure 7. An obvious feature is the large differences between background and the analysis fields. The 1D-Var retrieval has therefore been able (1) to shift the cyclone to the West by several degrees longitude in the Northern part of the area, (2) to create a second precipitating structure in the North East part of the cyclone which was completely missing in the background, and (3) to remove the major part of the three rain spots below longitude $129^{\circ}$ East.

[27] The analyzed rainwater distribution may be compared to surface rain rates derived from the algorithm of Bauer et al. [2000] to verify the general agreement of the rain structures (Figure 1). The cyclone's location and extent are very similar between the algorithm and the 1D-Var analysis. The three detached rain structures in the West of 

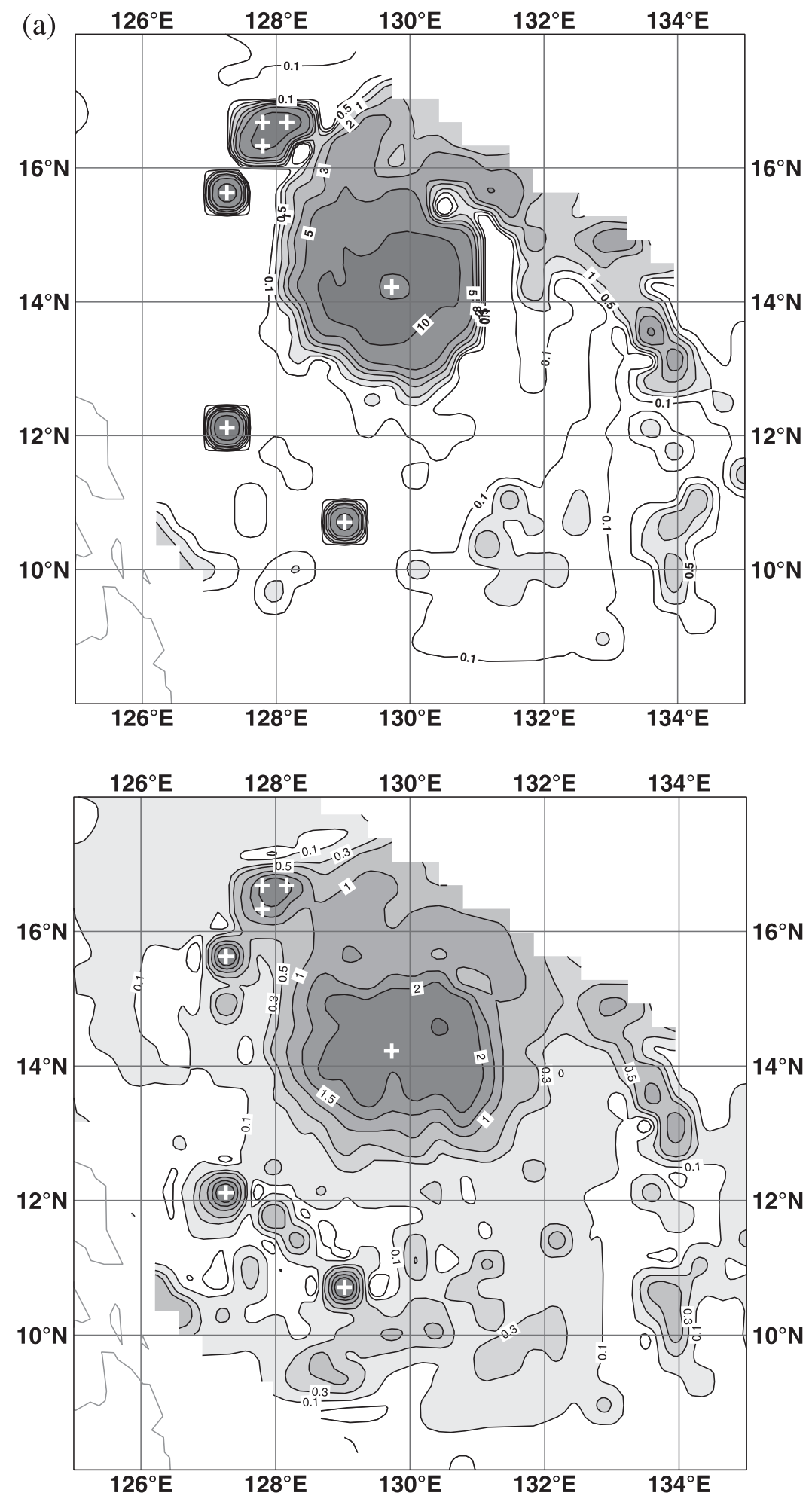

Figure 8. Surface rain rates in $\mathrm{mm} / \mathrm{h}$ (top) and cloud liquid water paths (bottom) in $\mathrm{kg} \mathrm{m}^{-2}$ from the analysis using channels at (a) 10.7, 19.35, and $21.3 \mathrm{GHz}$, (b) $19.35,21.3,37.0 \mathrm{GHz}$, and (c) 10.7, 19.35, $21.3,37.0 \mathrm{GHz}$

the storm center that were present in the background are not retrieved by either algorithm or variational retrieval.

\section{Channel Selection}

[28] To illustrate the influence of different microwave channels on the 1D-Var retrieval performance three experi- ments were carried out adding the $10.7 \mathrm{GHz}$ and $37.0 \mathrm{GHz}$ channels to those used in the control experiment. As discussed in Section 2.3, the channels at $19.35 \mathrm{GHz}$ saturate for high rainwater contents so that there is little or no sensitivity to rainwater content. This is where the $10.7 \mathrm{GHz}$ channels will improve the analysis. On the other hand, there is large sensitivity to cloud liquid water at $37 \mathrm{GHz}$ so that these 

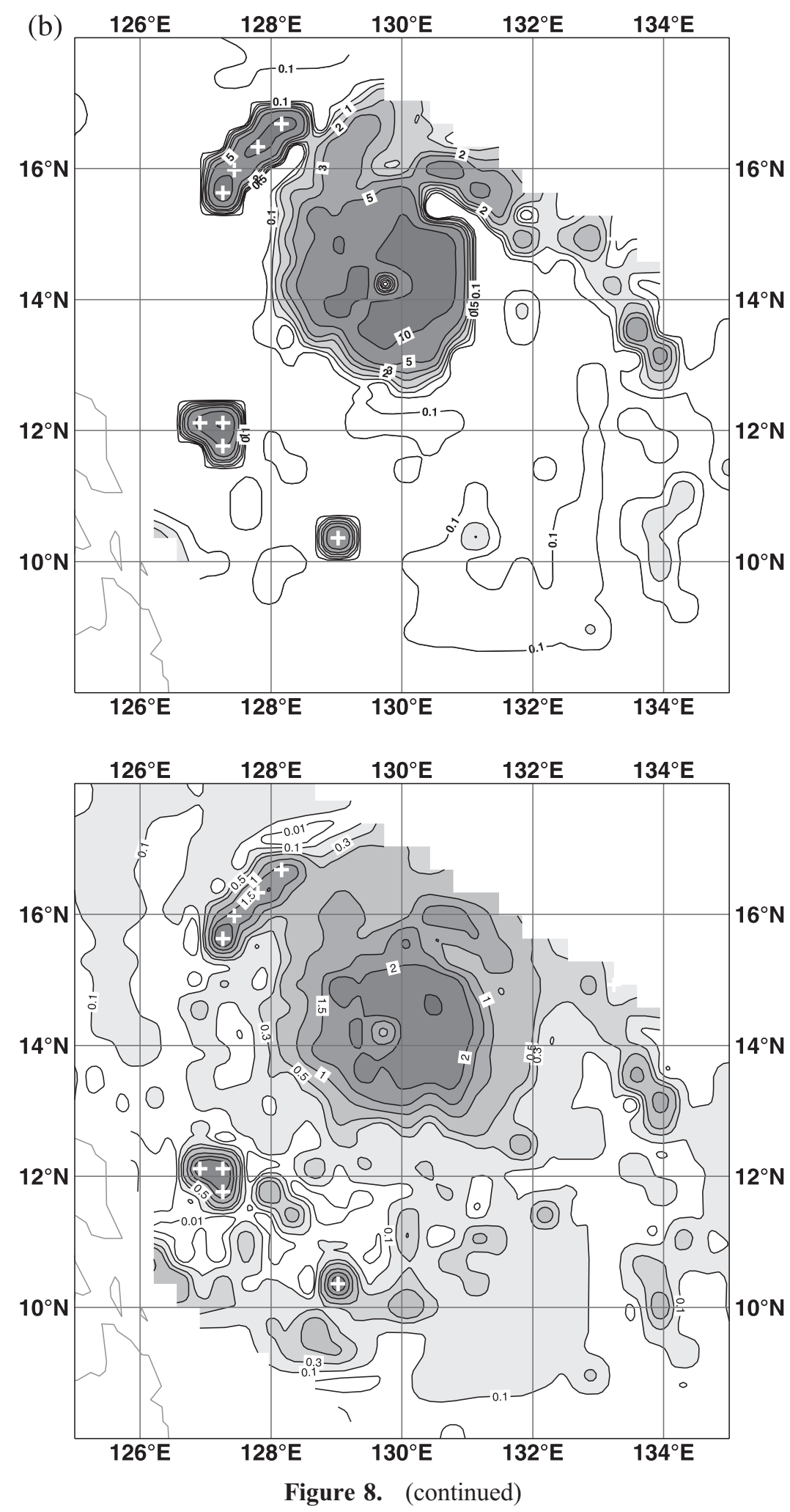

channels should provide complementary information on cloud vs. rainwater in the analysis.

[29] Three new experiments were set-up adding either 10v and $10 \mathrm{~h}($ test 1$), 37 \mathrm{v}$ and $37 \mathrm{~h}$ (test 2 ) or both channel pairs (test 3 ). As previously, the convergence of the 1D-Var retrieval for all test experiments was tested and is presented in Table 2 . The background departures are quite large again, with rmse s that reach $30.5 \mathrm{~K}$ at $10 \mathrm{~h}$ and $40.9 \mathrm{~K}$ at $37 \mathrm{~h}$ indicating the large difference between the background and the observations. For all experiments, the analysis departures are of the same order of magnitude as the observation errors. This demonstrates the good convergence of the 1D-Var minimization with the above described assumptions on errors and error correlations. By adding observations, i.e., in test 1 , test 2 , and test 3 , the analysis departures at $19 \mathrm{v}, \mathrm{h}$ and $21 \mathrm{v}$ slightly increase compared to the control experiment. This points to the combined effect of 
ACL $\quad 11-14$
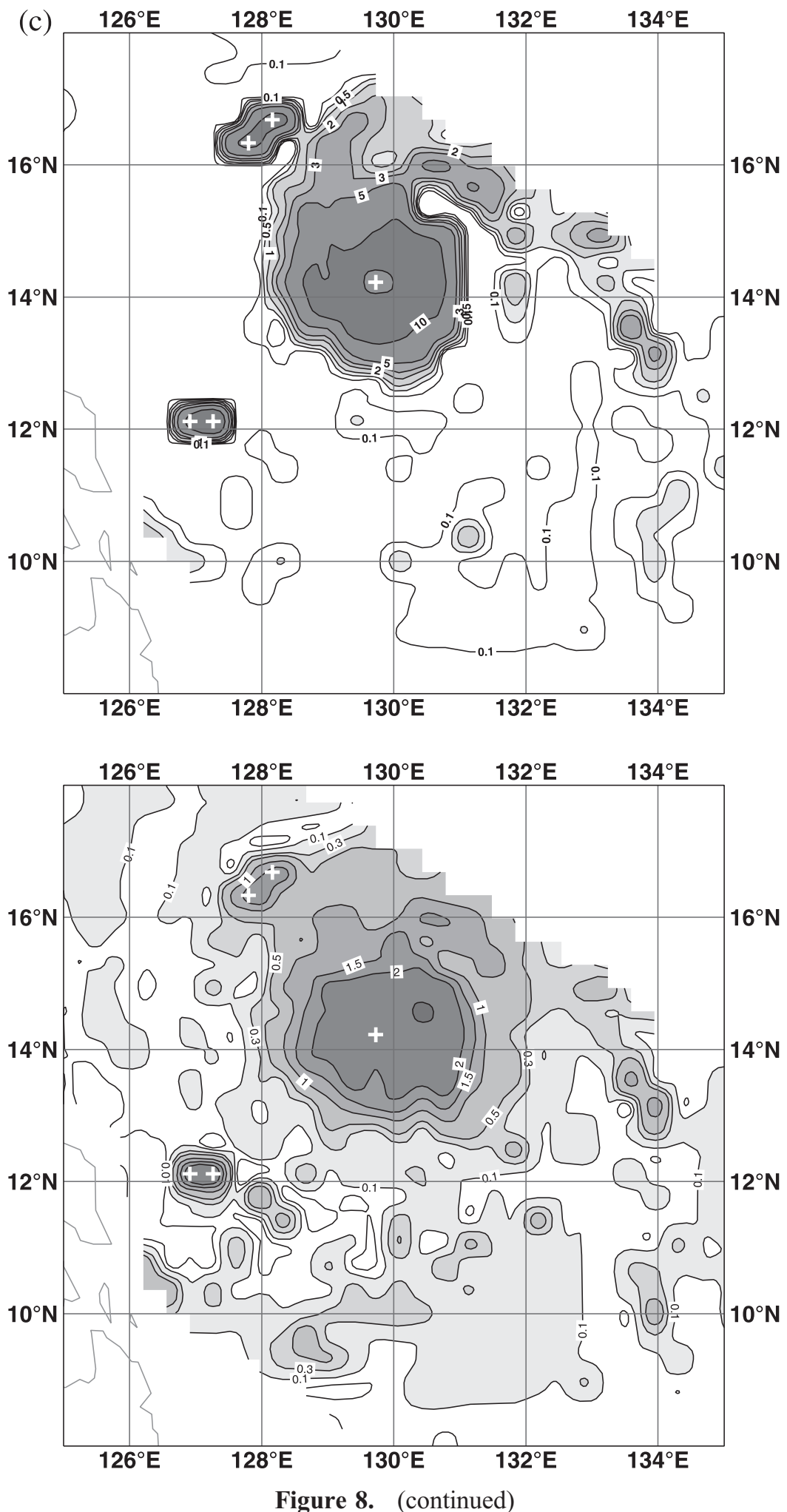

radiative transfer and cloud modeling errors which produces inconsistencies among channels. The biases behave as for the control experiment. At $37.0 \mathrm{GHz}$, quite substantial first-guess biases occur $(-11.4$ and $-24.0 \mathrm{~K}$ for the vertical and horizontal polarization, respectively) indicating that at this frequency the mismatch between model and observations for both clouds and light precipitation accumulates.
[30] The surface rain rates and the integrated cloud water fields for the test experiments are presented in Figure 8. As in the control experiment (in Figure 7), the analysis shifts the cyclone and produces a more circular structure. While these general features are produced by both control and test experiments, the test experiments exhibit some significant differences: 
Table 2. 1D-Var Statistics From Background and Analysis for Control and Test Experiments (see text for details) ${ }^{\mathrm{a}}$

\begin{tabular}{|c|c|c|c|c|c|c|c|}
\hline & $10 \mathrm{v}$ & $10 \mathrm{~h}$ & $19 \mathrm{v}$ & $19 \mathrm{~h}$ & $21 \mathrm{v}$ & $37 \mathrm{v}$ & $37 \mathrm{~h}$ \\
\hline \multicolumn{8}{|c|}{ Root Mean Square of the Background Departures $\mathbf{t b}^{o}-\mathbf{t b}^{b}$} \\
\hline Background & 16.6 & 30.5 & 17.2 & 33.6 & 9.2 & 19.7 & 40.9 \\
\hline \multicolumn{8}{|c|}{ Root Mean Square of the Analysis Departures $\mathbf{t b}^{o}-\mathbf{t b}^{a}$} \\
\hline Test 1 & 4.3 & 8.4 & 2.1 & 6.0 & 2.7 & - & - \\
\hline Test 2 & - & - & 3.1 & 6.4 & 3.0 & 4.1 & 7.2 \\
\hline Test 3 & 4.1 & 8.1 & 3.2 & 6.6 & 3.1 & 4.3 & $7.3 \backslash$ \\
\hline \multicolumn{8}{|c|}{ Bias/Standard Deviation of Background Departures $\mathbf{t b}^{o}-\mathbf{t b}^{b}$} \\
\hline Background & $-7.1 / 16.2$ & $-13.8 / 29.5$ & $-5.1 / 18.3$ & $-1.3 / 6.4$ & $-2.8 / 9.4$ & $-11.4 / 16.3$ & $-24.0 / 34.2$ \\
\hline \multicolumn{8}{|c|}{ Bias/Standard Deviation of Analysis Departures $\mathbf{t b}^{o}-\mathbf{t b}^{b}$} \\
\hline Test 1 & $-3.4 / 2.7$ & $-6.9 / 4.9$ & $0.4 / 2.1$ & $-3.4 / 4.9$ & $-0.1 / 2.7$ & - & - \\
\hline Test 2 & - & - & $1.6 / 2.7$ & $-1.1 / 6.3$ & $0.6 / 3.0$ & $-1.5 / 3.9$ & $-4.7 / 5.5$ \\
\hline Test 3 & $-2.8 / 3.0$ & $-5.9 / 5.5$ & $1.5 / 2.8$ & $-1.3 / 6.4$ & $0.6 / 3.0$ & $-1.1 / 4.2$ & $-4.3 / 5.8$ \\
\hline
\end{tabular}

[31] - The $10 \mathrm{GHz}$ channels (test 1 ) lead to an increase of rain and cloud water inside the cyclone and to a slight decrease of low cloud amounts in the vicinity.

[32] - The $37 \mathrm{GHz}$ channels (test2) slightly decrease the rain intensity and the cloud amount in the neighborhood of the cyclone (especially in its North-Eastern part).

[33] - The 10 and $37 \mathrm{GHz}$ channels together (test3) merge the particular influence of both frequencies by increasing both rain and cloud in the cyclone and by decreasing the cloud amount where rain intensities are small.More details are shown in Figure 9 by vertical cross-sections of rain and cloud liquid water profiles through the cyclone from the background, the control and the three test experiments, respectively. The rain and cloud water structures are similar in all test experiments and the removal of the convective cell near $127^{\circ} \mathrm{E}$ with respect to the control experiment is evident. The core of the cell near $130.5^{\circ} \mathrm{E}$ has been shifted by $0.5^{\circ}$ and largely intensified and widened. As described before, adding more channels influences the intensity of the rain and cloud water contents in the three test experiments. In the center of the cyclone (around $130^{\circ} \mathrm{E}$ ) with rainwater contents of $\approx 0.4 \mathrm{gm}^{-3}$ in the control experiment, $19 \mathrm{v}, 19 \mathrm{~h}$ and $21 \mathrm{v}$ are saturated, which means that an increases of the rain or cloud amount will lead only to a very small modification of the radiances. The addition of $10 \mathrm{v}$ and $10 \mathrm{~h}$ in test 1 , produces an increase of the rainwater content to up to $0.6 \mathrm{gm}^{-3}$ in the lower levels. The $37 \mathrm{GHz}$ channels used in test 2 produce a decrease in the amount of cloud and rainwater, as shown at $128.5^{\circ}$ and $133^{\circ} \mathrm{E}$. This is consistent with their sensitivity to cloud water. Adding both 10 and $37 \mathrm{GHz}$ channels (test 3 ), the effect of both frequencies are combined. An increase of rainwater (as in test 1 ) and a decrease of cloud water (as in test 2 ) are produced. Interestingly, both channels compensate their effect on cloud water in the structure located at $70^{\circ} \mathrm{E}$. The analyzed cloud water was decreased by the $10 \mathrm{GHz}$ channels and increased by the $37 \mathrm{GHz}$ channels but their combination produces cloud water distributions similar to the control experiment. This demonstrates the usefulness of both frequencies in order to separate sensitivities to cloud and rain water, that is to minimize aliasing. It is worth mentioning that test 2 was repeated with SSM/I data and led to the same conclusions as for TMI data.
[34] A more detailed insight into the limitations of the presented retrieval is provided by those cases where the retrieval did not converge during minimization. This occurs in the control experiment where rather heavy precipitation and large amounts of cloud water were present in the background but no clouds in the observation (see spots near $16^{\circ} \mathrm{N}$ and $128^{\circ} \mathrm{E}$ and $12^{\circ} \mathrm{N}$ and $128^{\circ} \mathrm{E}$ in Figures 7 and 8 ). Obviously, $19 \mathrm{v}, 19 \mathrm{~h}$, and $21 \mathrm{v}$ are nearly saturated and show too little sensitivity to eliminate both clouds and precipitation. This conclusion is supported by the fact that adding $37 \mathrm{v}$ and $37 \mathrm{~h}$ (Figure $8 \mathrm{~b}$ ) does not change the situation significantly because both $37 \mathrm{v}$ and $37 \mathrm{~h}$ are saturated as well. However, from test 1 already three out of eleven cases are resolved for which the precipitation reduction was the major obstacle. It is likely that by adding $85 \mathrm{v}$ and $85 \mathrm{~h}$, this number can be further reduced; however, the observation errors are more difficult to quantify because of the difference in spatial resolution and the rather uncertain model ice microphysics.

[35] In test3, all retrievals worked more successfully indicating that it takes complementary observational information on cloud and rainwater as well as a proper treatment of their inter-dependence by the constraints from the cloud/convection scheme and background error covariance matrices. Another case of non-convergence occurs in the storm center which is always present except in the control experiment. This is caused by the different spatial resolution of the TMI channels. The $10.7 \mathrm{GHz}$ channels perform a spatial smoothing and reduce spatial gradients observed in the other channels. During minimization the frequency dependent spatial imaging is transferred into hydrometeor profile modifications which may cause failures. This can only be avoided by either convolution of all channels to the same spatial resolution or by the explicit inclusion of spatial inhomogeneities in the forward and inverse models as a function of frequency. The problems associated with sub-grid scale variability and frequency dependent imaging will be the subject of a future study.

\section{Conclusions}

[36] For the first time, a methodology for the variational retrieval of cloud and precipitation profiles in the 

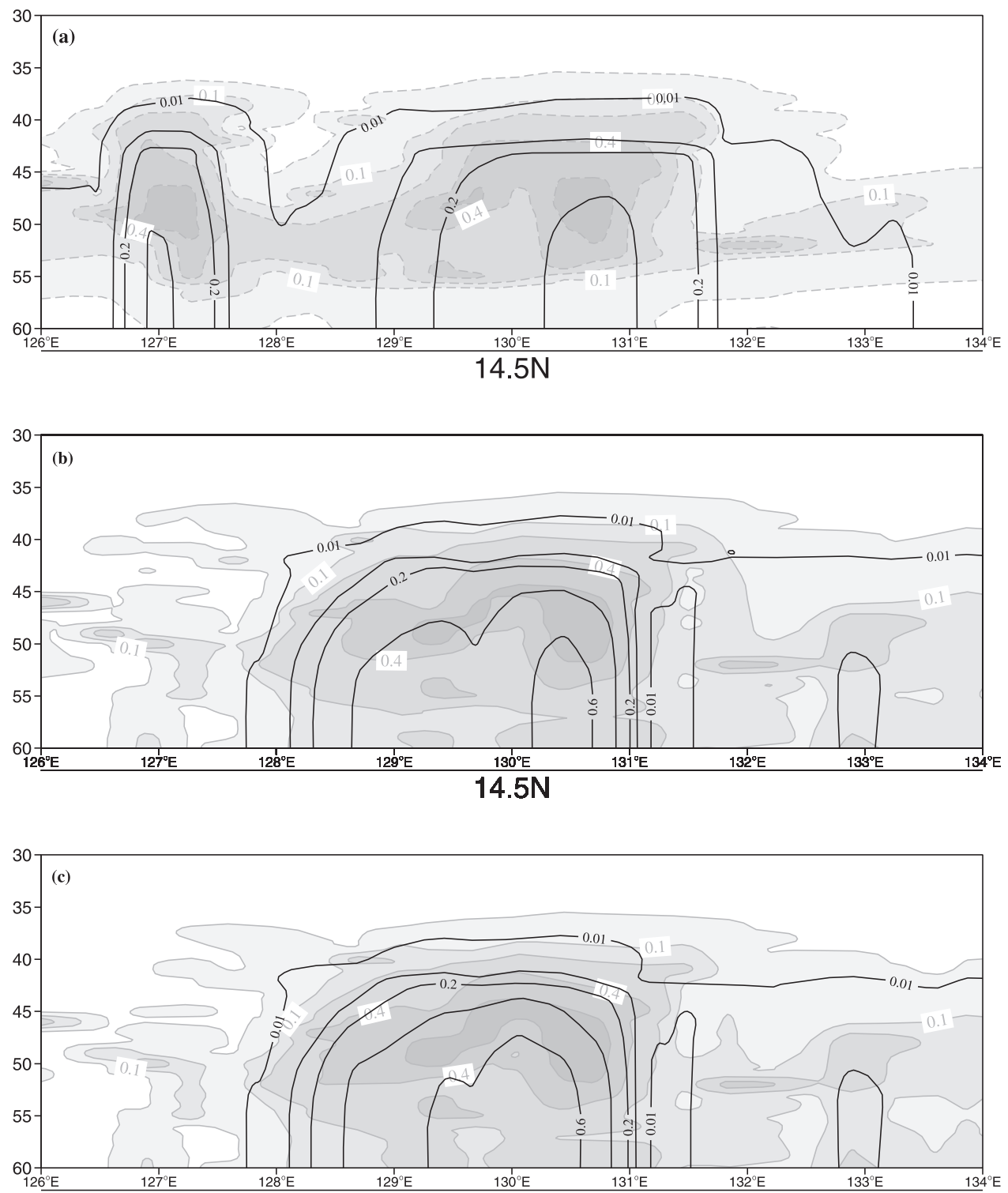

$14.5 \mathrm{~N}$

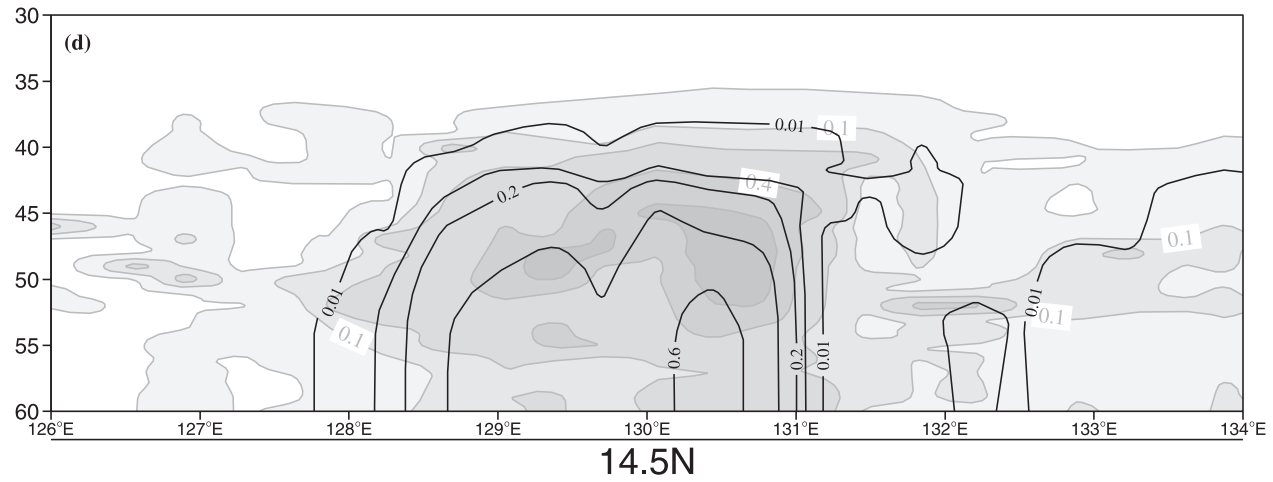

Figure 9. Vertical cross-section (see Figure 2) of rain water (solid lines) and cloud liquid water (dashed line) profiles from (a) background, (b) control experiment analysis, (c) including $10.7 \mathrm{GHz}$, (d) including 37.0 GHz, and (e) including 10.7 and $37.0 \mathrm{GHz}$. All units are in $\mathrm{gm}^{-3}$.

context of a numerical weather prediction framework is presented. This methodology is the basis for future efforts on assimilation of rain-affected passive microwave brightness temperatures measured by numerous operational
(SSM/I, AMSU) and research (TMI, AMSR) satellite radiometers.

[37] A numerically efficient radiative transfer model and its tangent-linear and adjoint versions have been developed 


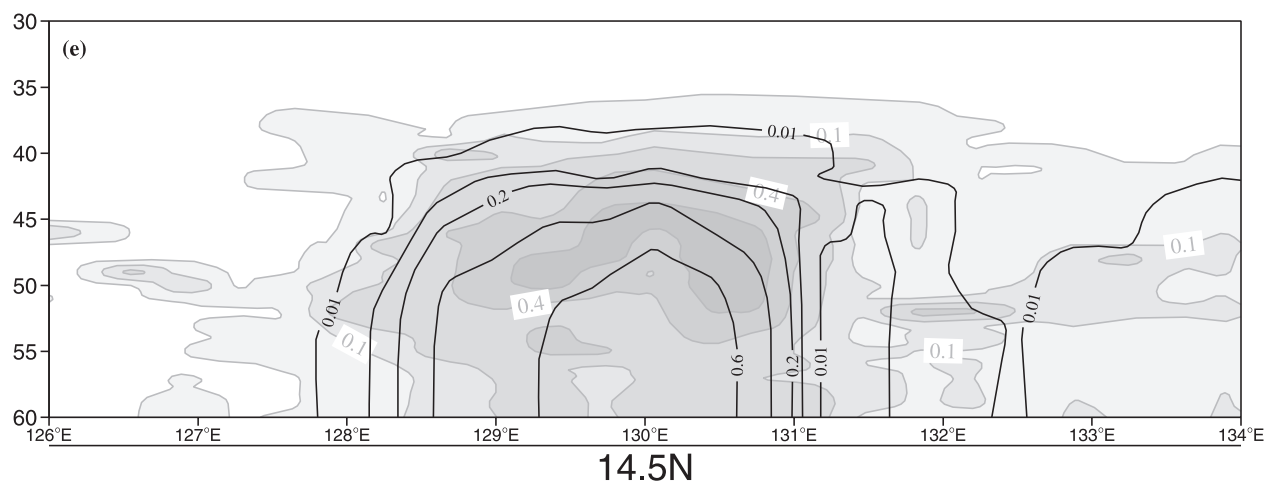

Figure 9. (continued)

because computation time is a crucial limitation for an operational implementation. The retrieval uses a variational approach that takes as its starting point profiles of temperature and humidity as well as hydrometeor profiles from a short-range ECMWF model forecast. The minimization is constrained by the errors associated with the first-guess state and the observations. The first-guess errors were obtained from a sensitivity study in which the operational first-guess errors of temperature and humidity serve as perturbations to the cloud and convection scheme. With a sufficient number of perturbations per profile first-guess errors and auto-/crosscorrelations of the hydrometeors can be produced. The observation errors were estimated from comparisons between the radiative transfer model and more accurate models as well as the instrumental noise. The non-linear response of brightness temperatures to cloud and rain hydrometeor contents also required the introduction of a convergence criterion to be applied after termination of the minimization.

[38] The methodology was tested on TMI data over a tropical cyclone (MITAG) which occurred in the Western Pacific Ocean on March 5, 2002. The calculation of Jacobians was used to demonstrate the sensitivity of different microwave frequencies to changes in hydrometeor contents. The retrieval method was applied using different microwave channel combinations. It could be shown that the optimum configuration was obtained by using all lower TMI channels, that is $10.7,19.35,21.3$, and $37.0 \mathrm{GHz}$. In this case, those profiles where a sub-selection of channels was leading to a failure in the minimization could be reduced and the differential sensitivity to clouds and precipitation could be maximized. By using either lower frequency $(10.7 \mathrm{GHz})$ or higher frequency $(37.0 \mathrm{GHz})$ channels a potential for aliasing cloud information into the rain analysis $(37.0 \mathrm{GHz})$ or vice versa $(10.7 \mathrm{GHz})$ was identified. Once all channels were used, only a single observation lead to a failed minimization. This was due to the different spatial resolution of the channels which can cause inconsistent observations. This problem will have to be further investigated.

[39] At this stage, the retrieval is limited to a onedimensional application. However, applied to three-dimensional fields the analyzed rainfall distributions resembled very closely those from an independent retrieval method. Despite the large difference between the model's first-guess fields and the analysis, the one-dimensional variational retrieval was able to eliminate and generate precipitation where there was too much or none in the observations. This way, the method was capable of 'moving' precipitation systems. The new feature of our approach with respect to conventional methods is to constrain the retrieval with forecast information, a consistent physical framework for convection and cloud formation as well as their uncertainties. This was made possible by the implementation of the numerically efficient radiative transfer modeling system. It has to be mentioned that there are large systematic modelobservation differences which mainly originate from too much cloud and precipitation in the model's first-guess [Chevalier and Bauer, 2003]. While the 1D-Var assimilation of radiances may correct these differences, their impact on the 4D-Var framework is not yet known. It is planned to develop a quality-control scheme that can account for (1) those observation for which the minimization will most likely fail and (2) reduce the number of observations to reduce the biases and therefore facilitate the four-dimensional assimilation of moisture increments.

[40] Open issues are whether the method can be implemented in the four-dimensional variational framework in the current configuration at ECMWF. For this, temperature and humidity have to represent the control vector and the sensitivities of brightness temperatures to hydrometeor contents and those of hydrometeor contents to temperature and moisture changes are combined. This requires efficient linearized models of convection and cloud schemes as well as their tangent-linear and adjoint versions. The utilization of a similar approach for precipitation as is used for clearsky radiances, i.e., a direct assimilation of radiances with an incremental formulation [Rabier et al., 2000] would require the reduction of sources of non-linearities in the minimization. This would lead to a reduction of channels at the expense of sensitivity to both clouds and precipitation. Following Marécal and Mahfouf [2002] a trade-off may be found by using a non-linear 1D-Var retrieval (as presented here) as a pre-processor for the 4D-Var assimilation system.

[41] Acknowledgments. The authors are grateful to the Numerical Weather Prediction Satellite Application Facility (NWP-SAF) for supporting the work on the fast radiative transfer model and to the European Space Agency for funding the EuroTRMM-2 project (contract 15418/01/NL/SE) in which the operational assimilation of rain information at ECMWF is prepared. We thank Jean-Noël Thépaut, Philippe Lopez, Adrian Tomkins, and Marta Janiskova for their support of the project and numerous discussions as well as Rob Hine for his help with the figures.

\section{References}

Bauer, P., Including a melting layer in microwave radiative transfer simulation for clouds, Atmos. Res., 57, 9-30, 2001. 
Bauer, P., Microwave radiative transfer modeling in clouds and precipitation: Part I. Model description, NWP-SAF rep. 5, 24 pp., Eur. Cent, Medium-Range Weather Forecast, Shinfield Park, Reading, U.K., 2002.

Bauer, P., P. Amayenc, C. D. Kummerow, and E. A. Smith, Over-ocean rainfall retrieval from multi-sensor data of the Tropical Rainfall Measuring Mission: part II. Algorithm implementation, J. Atmos. Oceanic Technol., $18,1838-1855,2001$.

Bauer, P., J.-F. Mahfouf, W. S. Olson, F. S. Marzano, S. di Michele, A. Tassa, and A. Mugnai, Error analysis of TMI rainfall estimates over ocean for variational data assimilation, Q.J.R. Meteorol. Soc., 128 , 2129-2144, 2002a.

Bauer, P., G. Kelly, and E. Andersson, Towards direct assimilation of SSM/I radiances in 4D-Var, paper presented at International TOVS Study Conference, Lorne, Victoria, Aust., 2002b.

Chevallier, F., and P. Bauer, Model rain and clouds over oceans: Comparison with SSM/I observations, Mon. Weather Rev., 131, 1240-1255, 2003.

Chevallier, F., P. Bauer, J.-F. Mahfouf, and J.-J. Morcrette, Variational retrieval of cloud liquid profile from ATOVS observations, Q.J.R. Meteorol. Soc., 128, 511-2526, 2002.

Courtier, P., J.-N. Thépaut, and A. Hollingsworth, A strategy for operational implementation of 4D-Var using an incremental approach, Q.J.R. Meteorol. Soc., 120, 1367-1388, 1994.

Deblonde, G., and S. J. English, Evaluation of the FASTEM-2 fast microwave oceanic surface emissivity model, Proc. Int. TOVS Study, 67-78, 2000 .

English, S., and T. J. Hewison, A fast generic millimetre wave emissivity model, Proc. SPIE Int. Soc. Opt. Eng., 3503, 22-30, 1998.

Eyre, J. R., A fast radiative transfer model for satellite sounding systems, ECMWF Tech. Memo. 176, 28 pp., Eur. Cent. Medium-Range Weather Forecasts, Reading U.K., 1993.

Harris, B. A., and G. Kelly, A satellite radiance-bias correction scheme for data assimilation, Q.J.R. Meteorol. Soc., 127, 1453-1468, 2001

Hollinger, J., J. L. Pierce, and G. A. Poe, SSM/I instrument evaluation, IEEE Trans Geosci. Remote Sens., 28, 781-790, 1990.

Hou, A. Y., D. V. Ledvina, A. M. da Silva, S. Q. Zhang, J. Joiner, R. M. Atlas, G. J. Huffman, and C. D. Kummerow, Assimilation of $\mathrm{SSM} /$ I-derived surface rainfall and total precipitable water for improving the GEOS analysis for climate studies, Mon. Weather Rev., 128, 509537, 2000.

Hufford, G. A., A model for the complex permittivity of ice, Int. J. Infrared Millimeter Waves, 12, 677-681, 1991.

Kummerow, C. D., On the accuracy of the Eddington-approximation for the radiative transfer in the microwave frequencies, J. Geophys. Res., 98, 2757-2765, 1993.

Kummerow, C., W. Barnes, T. Kozu, J. Shiu, and J. Simpson, The Tropical Rainfall Measuring Mission (TRMM) sensor package, J. Atmos. Oceanic Technol., 15, 809-817, 1998.

Krishnamurti, T. N., et al., Real-time multianalysis-multimodel superensemble forecasts of precipitation using TRMM and SSM/I products, Mon. Weather Rev., 129, 2861-2883, 2001.

Liebe, H. J., T. Manabe, and G. A. Hufford, Millimeter wave attenuation and delay rates due to fog/cloud conditions, IEEE Trans. Antennas Propag., 37, 1617-1623, 1989.
Lopez, P., Conception et validation d'une paramétrisation explicite des hydrométéores de grande-échelle, Evaluation de son potentiel dans les calculs adjoints, Ph.D. thesis, 216 pp., Univ. Paul Sabatier, Toulouse, France, 2001

Marécal, V., and J.-F. Mahfouf, Four-dimensional variational assimilation of total column water in rainy areas, Mon. Weather Rev., 130, 43-58, 2002.

Marécal, V., and J.-F. Mahfouf, Experiments on 4D-Var assimilation of rainfall data using an incremental formulation, Q.J.R. Meteorol. Soc., in press, 2003.

Marécal, V., J.-F. Mahfouf, and P. Bauer, Comparison of TMI rainfall estimates and their impact on 4D-Var assimilation, Q.J.R. Meteorol. Soc., 128, 2737-2758, 2002.

Moreau, E., P. Bauer, and F. Chevallier, Microwave radiative transfer modeling in clouds and precipitation: Part II. Model evaluation, NWP-SAF rep. 5, 20 pp., Eur. Cent., Medium-Range Weather Forecast, Shinfield Park, Reading, U.K., 2002.

Parrish, D. F., and J. C. Derber, The National Meteorological Center's spectral statistical interpolation analysis system, Mon. Weather Rev., 120, 1747-1763, 1992

Rabier, F., A. McNally, E. Andersson, P. Courtier, P. Unden, J. Eyre, A. Hollingsworth, and F. Bouttier, The ECWMF implementation of three-dimensional variational assimilation (3D-Var): Part II. Structure functions, Q.J.R. Meteorol. Soc., 124, 1809-1829, 1997.

Rabier, F., H. Järvinen, E. Klinker, J.-F. Mahfouf, and A. Simmons, The ECMWF operational implementation of four-dimensional variational assimilation, Q.J.R. Meteorol. Soc., 126, 1143-1170, 2000.

Saunders, R., P. Brunel, F. Chevallier, G. S. Deblonde, J. English, M. Matricardi, and P. Rayer, RTTOV-7 Science and validation report, Met Office Forecasting and Res., Technical Rep., 387, 51 pp., 2001.

Smith, E. A., P. Bauer, F. S. Marzano, C. D. Kummerow, D. McKague, A. Mugnai, and G. Panegrossi, Intercomparison of microwave radiative transfer models for precipitating clouds, IEEE Trans. Geosci. Remote Sens., 40, 541-549, 2002.

Tassa, A., S. Di Michele, A. Mugnai, F. S. Marzano, and J. P. V. Poiares Baptista, Cloud model-based Bayesian technique for precipitation profile retrieval from the Tropical Rainfall Measuring Mission Microwave Imager, Radio Sci., 38(4), 8074, doi:10.1029/2002RS002674, 2003.

Tiedtke, M., A comprehensive mass flux scheme for cumulus parameterization in large scale models, Mon. Weather Rev., 117, 1779-1800, 1989.

Tiedtke, M., Representation of clouds in large scale models, Mon. Weather Rev., 121, 3040-3061, 1993.

Treadon, R. E., Assimilation of satellite derived precipitation estimates with the NCEP GDAS, Ph.D. thesis, 348 pp., Florida State Univ., Tallahassee, Fla., 1997.

E. Moreau, P. Bauer, and F. Chevallier, European Centre for MediumRange Weather Forecasts, Shinfield Park, Reading Berkshire RG2 9AX, UK. (emmanuel.moreau@ecmwf.int) 